\title{
Microstructural and Corrosion Characteristics of Iron-Silicon Alloyed Layer on 5083 Al Alloy by Electrical Discharge Alloying Processing
}

\author{
Hung-Mao $\operatorname{Lin}^{1, * 1}$, Stambekova Kuralay ${ }^{2, * 2}$ and Jun-Yen $\operatorname{Uan}^{2}$ \\ ${ }^{1}$ Department of Mechanical Engineering, Far East University, No. 49, Zhong Hua Rd., \\ Xinshi Dist., Tainan City 74448, Taiwan, R.O.China \\ ${ }^{2}$ Department of Materials Science and Engineering, National Chung Hsing University, \\ 250 Kuo Kuang Rd., Taichung 402, Taiwan, R.O.China
}

In the study, the surface modification of $5083 \mathrm{Al}$ alloy by electrical discharge alloying (EDA) with a 75 mass $\%$ ferrosilicon electrode was used to examine the effects of machining parameters (discharge current, pulse duration and duty factor) on the thickness, hardness and surface roughness of the alloyed layer. Experiment results reveal that the thickness tends to increase with the increase in the pulse duration and discharge current. In addition, the micro-hardness evidently higher compared to the substrate. The hardness also increases with the increasing discharge current and pulse duration. TEM examinations show that the matrix of the alloyed layer is an amorphous-like structure, whereas the matrix contains fine needle-like Si particles, block-like Si particles and nano-size $\mathrm{Al}_{4.5} \mathrm{FeSi}$ and $\mathrm{Al}_{13} \mathrm{Fe}_{4}$ particles. The results of EPMA compositional analysis indicate that the alloying elements $(\mathrm{Si}$ and $\mathrm{Fe}$ ) contained in the electrode effectively dissolve in the alloyed layer of $5083 \mathrm{Al}$ alloy and the content of the dissolved alloying elements gradually decreases with the increase in the distance from the discharge surface. Furthermore, the surface roughness increases with the increase in the discharge current and pulse duration. It is also found that the alloyed layer with composite microstructures exhibits sufficient corrosion resistance to $\mathrm{NaCl}$ aqueous solutions. [doi:10.2320/matertrans.M2010363]

(Received October 18, 2010; Accepted December 3, 2010; Published February 9, 2011)

Keywords: electrical discharge alloying, ferrosilicon electrode, machining parameter, 5083 aluminum alloy

\section{Introduction}

Aluminum Alloy 5083 has been widely used in the marine, cars, aircrafts, unfired welded pressure vessels, cryogenics, TV towers, drilling rings, transportation equipment, missile components and armor plates. It features very good corrosion resistance, weldability and strength. It also has good forming characteristics for either hot or cold working and shows excellent weldability in conventional methods. Hardening is accomplishable only by means of cold working. ${ }^{1)}$ Aluminum alloy typically has relatively low hardness, which often needs modification especially for making sliding components with high load bearing. This explains why Al mechanical components are severely worn in a rapid manner particularly in the case of sliding contact. In view of the increasingly harsh environments in which $\mathrm{Al}$ alloy components are used, it is necessary to improve the surface properties of aluminum alloy in order to obtain surface layers with both great hardness and excellent corrosion resistance. Hence, easy, low-cost surface modification warrants further study. Surface modification may improve the performance of mechanical components, and may enhance their service life.

Some studied have investigated the surface modification through the use of electrical discharge machining $(E D M){ }^{2-10)}$ Electrical discharge alloying (EDA) is a surface modification method using a conventional electrical discharge machining (EDM) machine. The electrode and the substrate bulk are molten with the electric arc between them to alloy the substrate surface with the electrode. The EDA has recently been used as a new surface alloying technique for improving the surface properties, both chemical and mechanical, of structural materials (such as Al- or Fe-based

\footnotetext{
${ }^{* 1}$ Corresponding author, E-mail: hungmaolin@cc.feu.edu.tw

${ }^{* 2}$ Graduate Student, National Chung Hsing University
}

alloys). ${ }^{3-10)}$ Mohri et al. ${ }^{6)}$ carried out surface modification on workpieces of carbon steel and aluminum using composite electrodes of copper, aluminum, tungsten carbide and titanium in hydrocarbon oil. The existence of electrode materials in the surface layers of workpieces significantly changes the characteristics of these layers. These surfaces had less cracks and higher resistance against corrosion and wear. Another study on the surface modification of aluminum was done by Tsunekawa et al. ${ }^{7)}$ using powder compact electrodes having 64 mass $\% \mathrm{Ti}$ and 36 mass\% $\mathrm{Al}$ and they obtained fine dendritic precipitates of titanium carbide on the machined surface. Electrodes were connected to negative polarity and kerosene was used as the working fluid. The average diameter and alloying depth of discharge craters increased with the increase in the pulse duration, the other important factor being the discharge current. The forming pressure of the powder metallurgy electrodes was found not to affect material transfer. The EDMed surface indicated effective improvements of various characteristics such as hardness, tribological properties and wear/corrosion resistance. Therefore, the EDA method is used in the study to modify the surface of $5083 \mathrm{Al}$ alloy and a silicon-iron layer on the surface is obtained by means of alloying using $\mathrm{Fe}-75$ mass\% Si alloy electrode materials. The purpose is to examine the relationship between machining parameters (discharge current, pulse duration and duty factor) for EDA and the microstructural characteristics of the layer. The ensuing findings serve as the reference basis for adopting the process that modifies the $5083 \mathrm{Al}$ alloy by means of EDA using a ferrosilicon electrode.

\section{Experimental Procedures}

\subsection{Electrical discharge alloying process}

Table 1 shows the composition of the $5083 \mathrm{Al}$ alloy used 
Table 1 Chemical composition of the AA5083 alloy (in mass\%).

\begin{tabular}{ccccccccc}
\hline $\mathrm{Cu}$ & $\mathrm{Si}$ & $\mathrm{Fe}$ & $\mathrm{Mn}$ & $\mathrm{Mg}$ & $\mathrm{Zn}$ & $\mathrm{Cr}$ & $\mathrm{Ti}$ & $\mathrm{Al}$ \\
\hline 0.10 & 0.4 & 0.40 & 1.0 & 4.9 & 0.25 & 0.25 & 0.15 & bal. \\
\hline
\end{tabular}
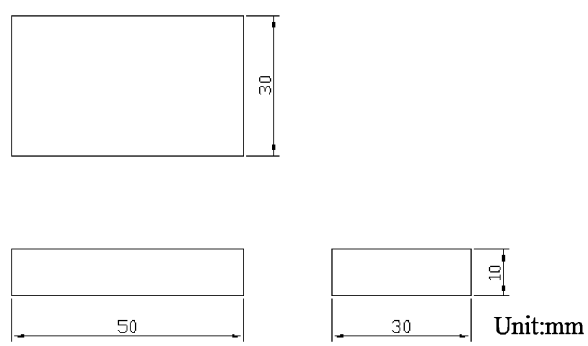

Fig. 1 Dimension of alloying specimens.

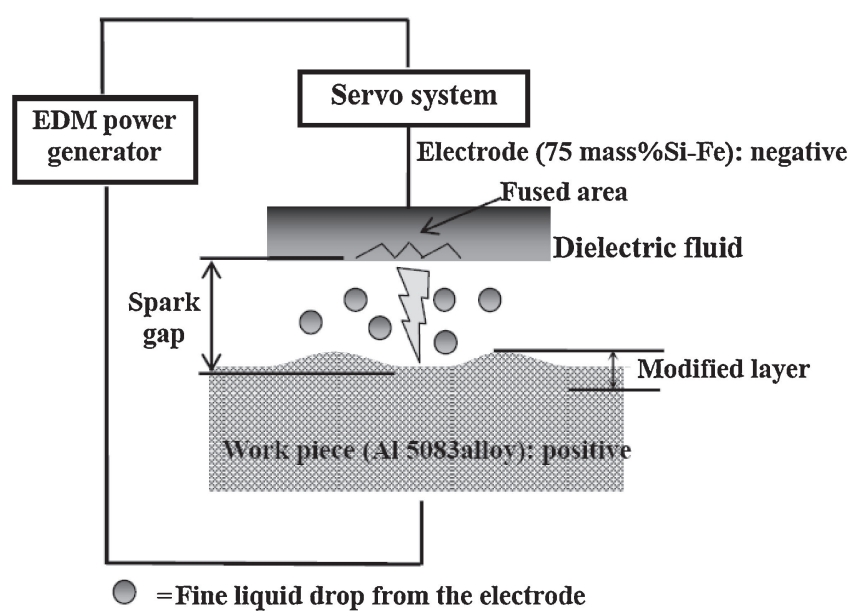

Fig. 2 Schematic of EDA process.

Table 2 Parameters of the electrical discharge machining.

\begin{tabular}{cc}
\hline Electrode & Fe-75 mass $\%$ Si \\
\hline Specimen & AA 5083 alloy \\
\hline Working area & $50 \times 30\left(\mathrm{~mm}^{2}\right)$ \\
\hline Current & $10 \sim 50(\mathrm{~A})$ \\
\hline Pulse duration & $100 \sim 1000(\mu \mathrm{s})$ \\
\hline Duty factor $(\%)$ & $25,33,40,50$ \\
\hline Dielectric fluid & Kerosene \\
\hline Fluid pressure & $1\left(\mathrm{~kg} / \mathrm{mm}^{2}\right)$ \\
\hline Working Time & Working Time: $30 \mathrm{~min}$ \\
\hline
\end{tabular}

in this study. Figure 1 illustrates the dimensions of the alloying specimen. The surface area of the part having received EDA on the sample is $50 \times 30 \mathrm{~mm}^{2}$. Figure 2 displays a schematic diagram of the EDA process. Table 2 lists the electrical discharge conditions.

\subsection{SEM observation and EPMA element analysis}

The surface morphology and cross-sectional microstructures of the sample were observed using SEM. The EPMA/ mapping and line scanning analysis investigated the distribution of elements around the alloyed layer of the surface obtained by using EDA.

\subsection{Measurement of hardness, thickness and roughness measurement of the alloyed layer}

To determine the effects of experimental conditions for the EDA process on the hardness of the alloyed layer, a Vickers micro-hardness tester was used to examine the hardness of the cross section of the alloyed specimen from the surface to the substrate. For the measurement of thickness, The means hardness of the alloyed layer was obtained from the thickness dimensions of 15 alloyed layers obtained by using SEM with a fixed magnification of 1000 times. The surface roughness (Ra) of the alloyed layer was obtained by using a roughness tester. Each of the several layer groups traveled for a distance of $5 \mathrm{~mm}$. The mean of three measures for each group was then calculated.

\subsection{Corrosion testing}

Electrochemical polarization tests were conducted at a scan rate of $0.5 \mathrm{mVs}^{-1}$ in a corrosion cell containing $300 \mathrm{ml}$ 3.5 mass $\% \mathrm{NaCl}$ aqueous solution at room temperature. Open-circuit potential (OCP) measurement were done while the alloyed layer sample was immersed in a $50^{\circ} \mathrm{C}_{\mathrm{HCO}_{3}}{ }^{-} /$ $\mathrm{CO}_{3}{ }^{2-}$ solution with a $\mathrm{pH}$ of 11.5 . All electrochemical measurements were done by using a Princeton Applied Research model $263 \mathrm{~A}$ potentiostat/galvanostat and the M352 software. A silver/silver chloride $(\mathrm{Ag} / \mathrm{AgCl})$ electrode served as the reference electrode. The concentration of the internal electrolyte in the reference electrode is $3.5 \mathrm{M} \mathrm{KCl}$ solution. A platinum flake was used as the counter electrode. The surface area of the sample exposed to the $\mathrm{NaCl}$ solution was $1 \mathrm{~cm}^{2}$. Anodic and cathodic polarization curves were generated for each of the different machining parameter specimens.

\subsection{TEM observations and XRD analysis}

The TEM sample was prepared for cross section observations using the focused ion beam (FIB) technique (FEI NOVA-600). Excess materials were removed by the ion beam from both sides of the region of interest until a thin specimen of roughly $100 \mathrm{~nm}$ was obtained. An FEI Tecnai F20 transmission electron microscope was utilized to examine the microstructure of the alloyed sample layer with an applied voltage of $200 \mathrm{kV}$. The X-ray diffraction analysis was also used in the study to identify the structure of the alloyed layers and compare the difference in structure between the layers that respectively received and did not receive the alloying treatment.

\section{Results and Discussion}

\subsection{SEM observation of EDAed layer}

When spark discharge occurred, the machined surfaces were shortly heated to $12,000^{\circ} \mathrm{C}$ followed by rapid cooling. ${ }^{11)}$ As a result, the remaining superficial layers on the machined surfaces underwent modification and significant properties other than those of the base metal. From the observations of the EDAed topographical surface appearances in Fig. 3, the defects on the surfaces of the alloyed layers include solidification structures, pores, craters and cracks etc. Figure 4 illustrates the SEM observations of the cross-sections of the layers on $5083 \mathrm{Al}$ alloy that were modified by using EDA. 


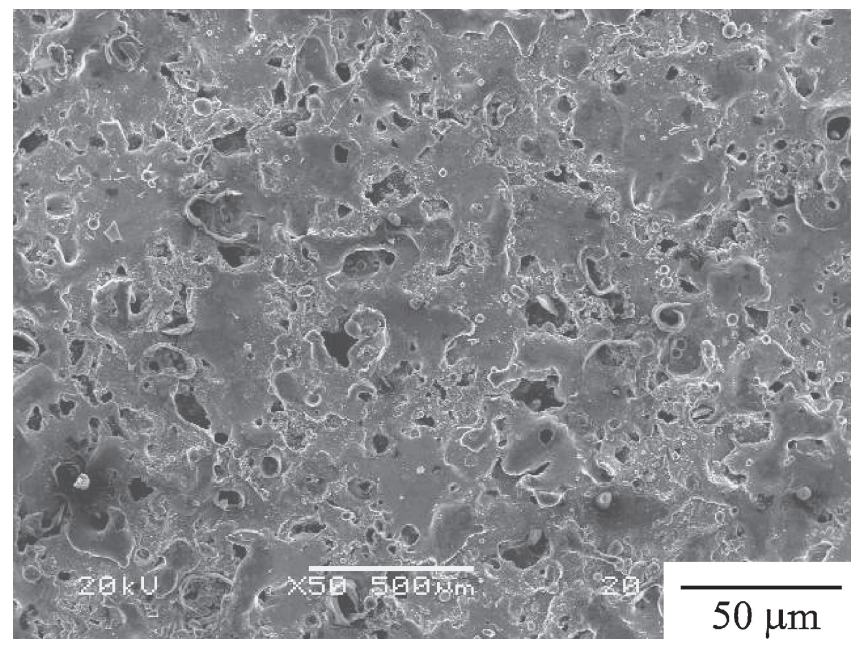

Fig. 3 SEM topographical surface image of EDA specimen.

Figures 3 and 4 reveal the existence of cracks in the alloyed layers. They were the result of the tensile stress inside the alloyed layers that arose from melting and cooling within a short time. Figure 5 is the EPMA/line scan analysis profile of the resultant alloyed layers by using the $\mathrm{Fe}-75$ mass $\% \mathrm{Si}$ electrode and indicates a marked increase of silicon and iron in the layers. Figure 6 illustrates the results of the EPMA/ mapping analysis on the resultant alloyed layers by using the Fe-75 mass\% Si electrode. These results indicate that the silicon and iron elements were dissolved into the layers and caused a marked increase in the hardness of the layers.

\subsection{Effects of machining parameter on the thickness, hardness and roughness of the alloyed layer}

Furthermore, Fig. 5 reveal a increasing discharge current of $5083 \mathrm{Al}$ alloy surface leads to increase silicon and iron concentration of the alloying layer which contribute to improved hardness of silicon alloying modified layer. Figures 7(a) and 8(a) display that the thickness and hardness of the alloyed layer increase with the increase in the

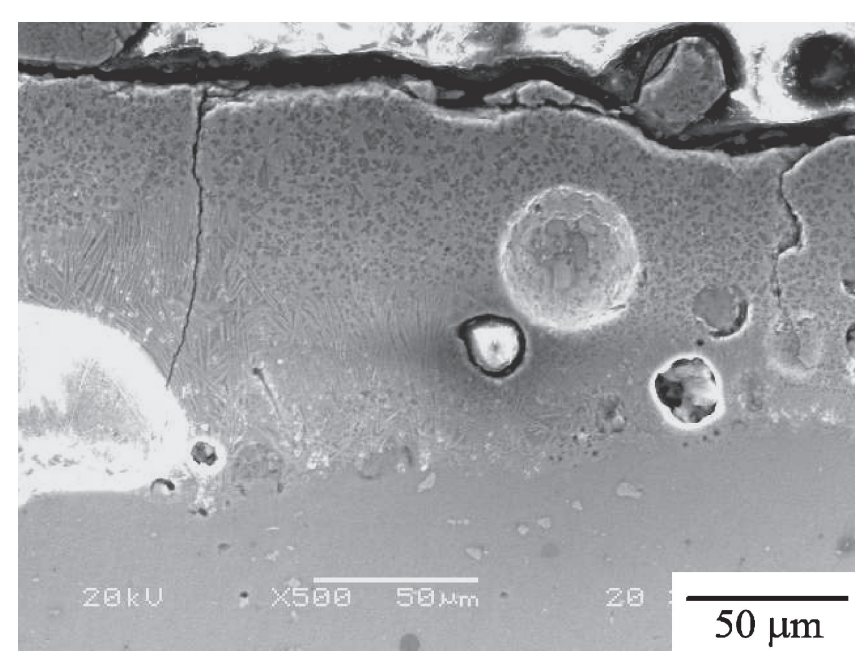

Fig. 4 SEM cross-section micrograph of alloying layer.

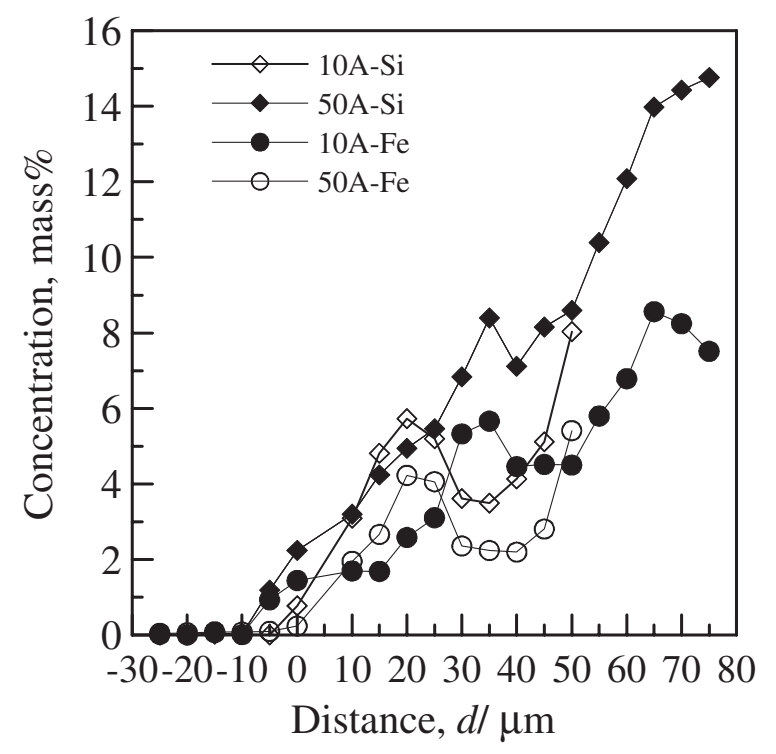

Fig. 5 EPMA/line scan profile of $\mathrm{Si}$ and Fe concentration of EDAed specimen.
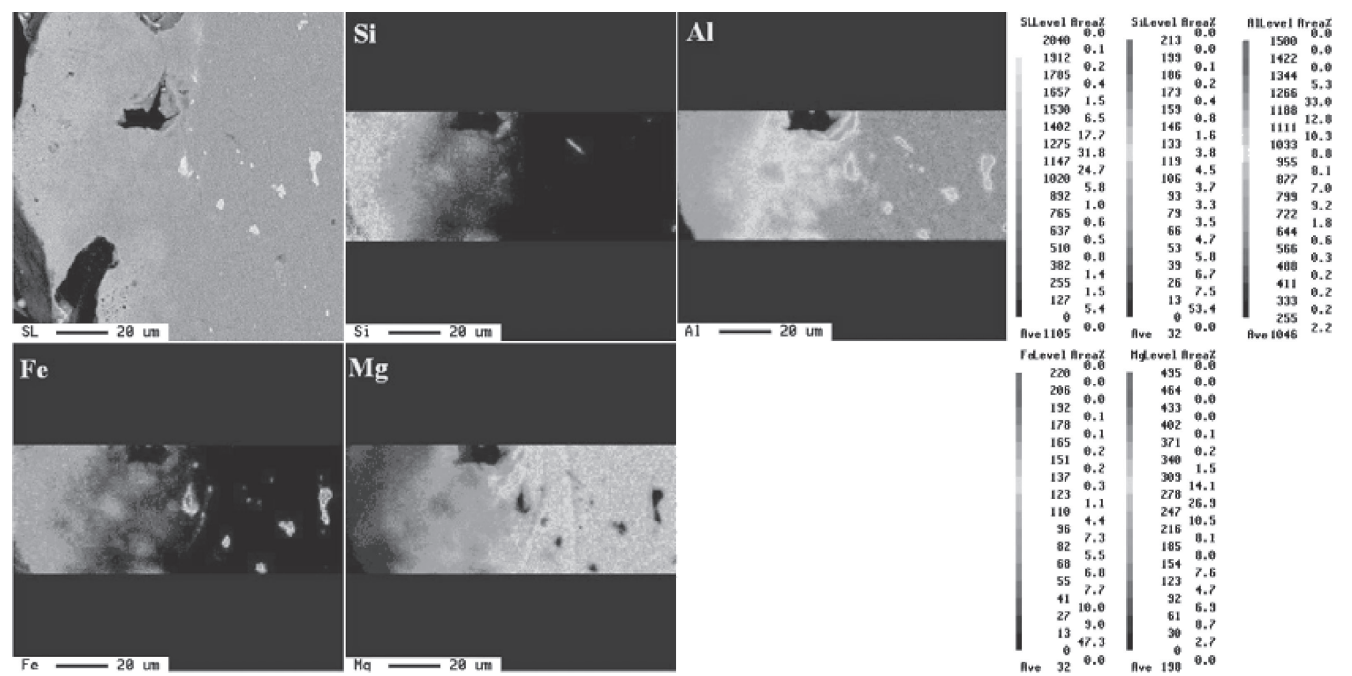

Fig. 6 EPMA/mapping of the EDAed layer. 

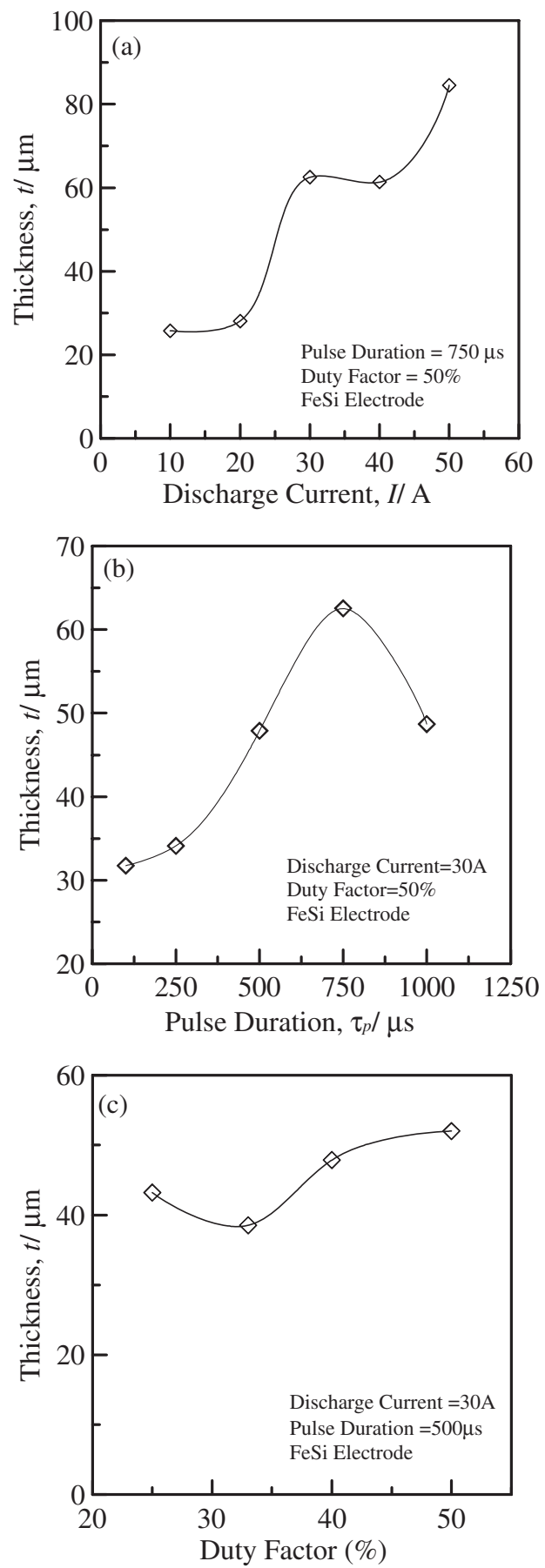

Fig. 7 Dependence of thickness of EDAed layer vs. different machining parameter.

discharge current. Figure 5 further reveals an increased discharge current applied to the surface of the $5083 \mathrm{Al}$ alloy leads to the increased silicon and iron concentration in the alloyed layer which contributes to the improved hardness of the layer that has received alloying modification by using ferrosilicon electrode. As for the difference in the machining parameter, pulse duration, there is a parallel increase between the thickness and hardness of the layer with the pulse duration increasing. When the duration is $1000 \mu \mathrm{s}$, the thickness noticeably decreases, as revealed in Figs. 7(b) and $8(\mathrm{~b})$. In the investigation of the relationship between the machining parameter, duty factor, and the characteristics
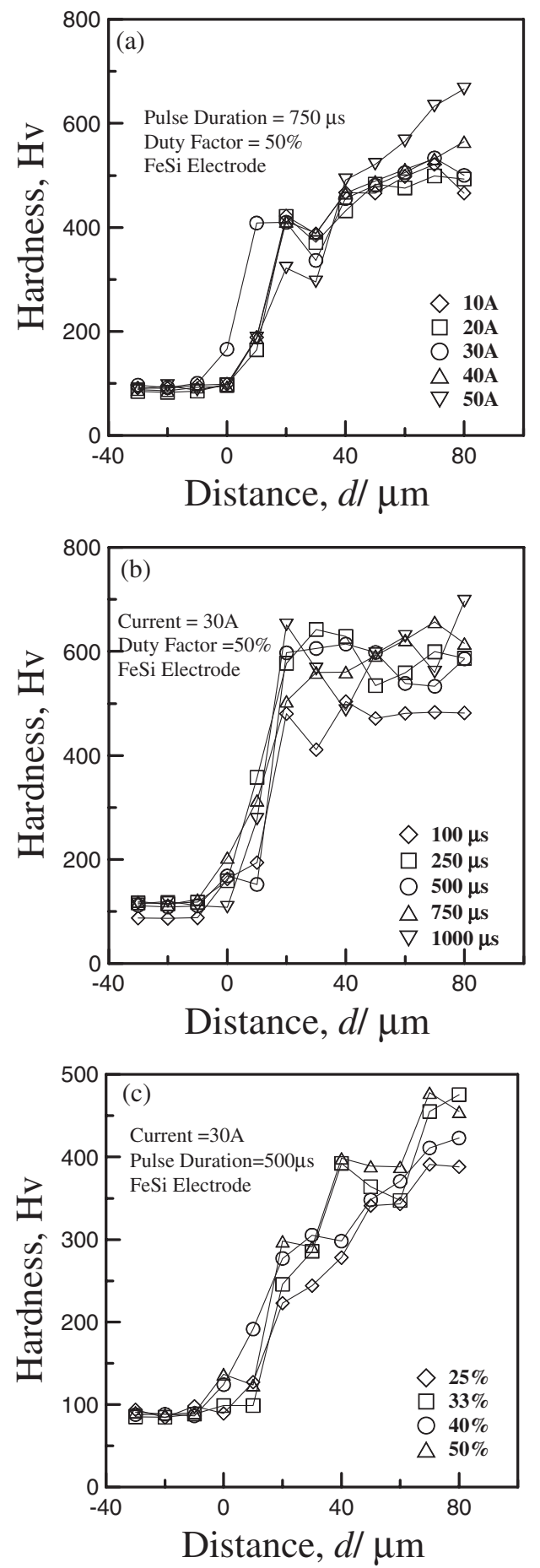

Fig. 8 Profile of micro-hardness of EDAed layer vs. different machining parameter.

of the alloyed layer, the thickness and hardness of the layer are found to have reached their maximum when the duty factor is 50\%, as shown in Figs. 7(c) and 8(c). In Fig. 9, the measured roughness of several alloyed layers show a parallel increase between the roughness of the layer and the discharge current. The surface of the layer is less rough when the pulse duration is $500 \mu$ s compared to any duration lower or higher than $500 \mu \mathrm{s}$, during which surface of the layer is markedly rougher. In addition, the alloying layer surface has the optimal roughness when the duty factor is $50 \%$. 

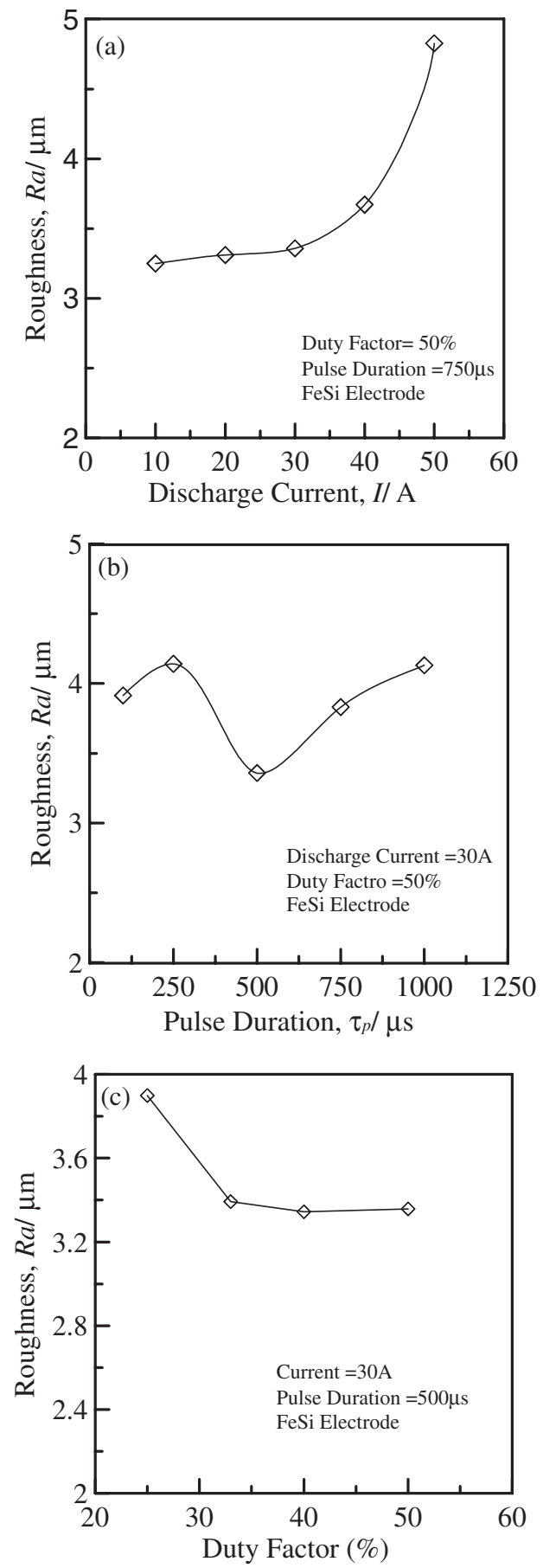

Fig. 9 Surface roughenss of EDAed specimens vs. different machining parameter.

\subsection{Polarization behavior}

Polarization curves of the Fe-Si alloyed layer obtained with different machining parameters (discharge current, pulse duration and duty factor) indicate that the anodic curves of both the layer and the overlap match and their cathodic curves also match, as shown in Fig. 10. However, there is a tendency of parallel increase between the current density of the layer in the passivation region and the discharge current when the fixed potential is $-0.75 \mathrm{~V}$ while the density shows no evident change in the same condition when the pulse duration and duty factor vary and the fixed potential remains at $-0.75 \mathrm{~V}$. The noticeable results illustrate
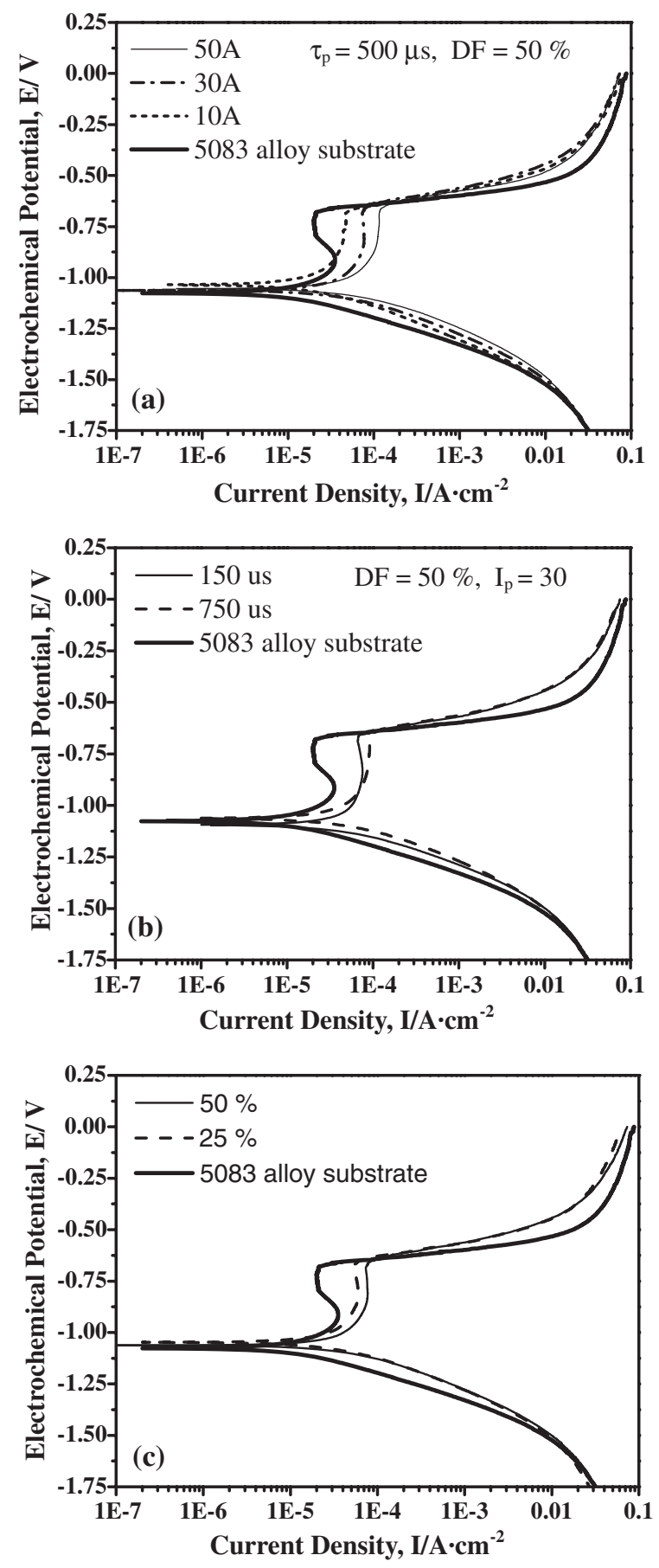

Fig. 10 Polarization curves of different machining parameter alloying specimens in 3.5 mass\% $\mathrm{NaCl}$ aqueous solutions.

that the corrosion resistance of the layer tends to reduce with the increase in the discharge current.

\subsection{TEM observation and XRD analysis}

Figure 11(a) shows the TEM cross-sectional microstructure of the alloyed layer. Selected area diffraction (SAD) patterns were taken from a needle-like particle (Fig. 11(b)), a block-like particle (Fig. 11(c)), and an amorphous-like matrix (insert in Fig. 11(d)). Figure 11(d) also shows a highresolution image of the matrix. The SAD patterns display a diffuse diffraction ring and some diffraction spots, suggesting that some crystals exist in the amorphous matrix. 

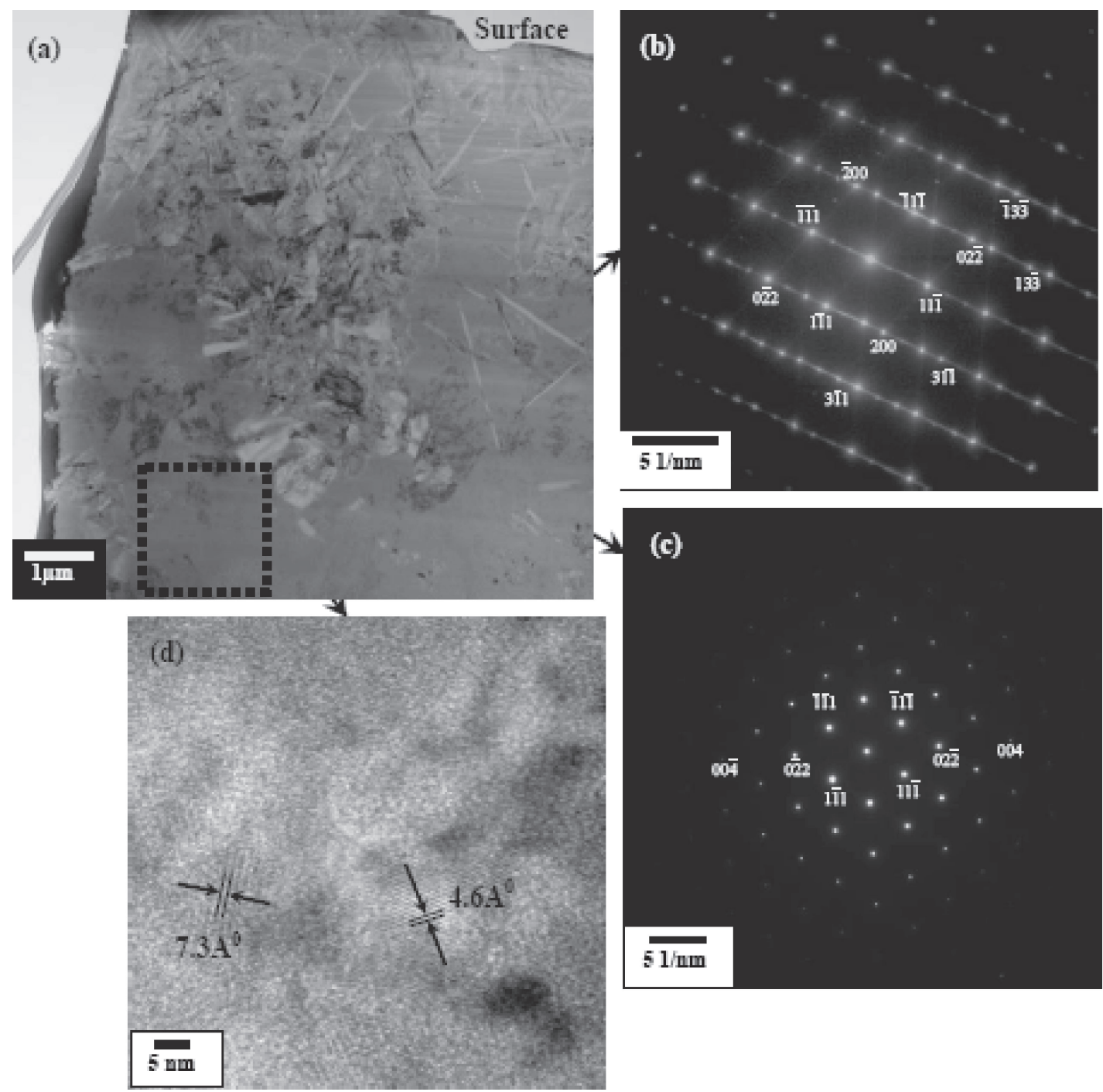

Fig. 11 TEM cross-section microstructure of (a) the alloying layer, selected area diffraction (SAD) patterns: (b) needle-like particle, (c) block-like particle and (d) amorphous-like matrix.

Figure 11(d) shows a high-resolution TEM image, indicating that the amorphous matrix consists of some nano-sized crystals. According to interplanar spacing measurements using high-resolution images (Fig. 11(d)), interplanar spacing was about $0.46 \mathrm{~nm}$, which corresponds to the $\mathrm{Al}_{4.5} \mathrm{FeSi}$ compound, and about $0.73 \mathrm{~nm}$, which corresponds to the $\mathrm{Al}_{13} \mathrm{Fe}_{4}$ compound. The results of X-ray diffraction on the alloyed layer shows that $\mathrm{Si}, \beta \mathrm{Al}, \mathrm{Al}_{3} \mathrm{Fe}$ and $\mathrm{AlFeSi}$ are the primary phases, as shown in Fig. 12.

\section{Conclusions}

(1) Regarding the Fe-Si alloyed layer in the surface of 5083 Al alloy obtained from the surface modification with a ferrosilicon electrode, its thickness and hardness increases with the increase in the discharge current and its surface roughness also shows the same tendency.

(2) As examined with different pulse durations, the thickness and hardness of the layer generally increases with the increase in the duration with the exception that the thickness remarkably decreases when the duration is

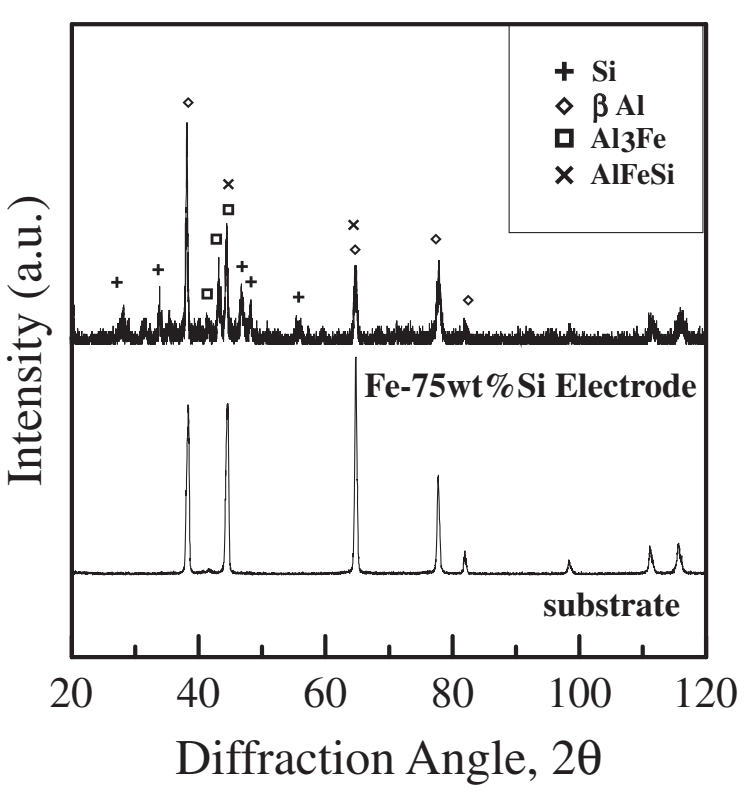

Fig. 12 XRD patter of EDAed specimen. 
$1000 \mu \mathrm{s}$. The surface is less rough when the duration is $500 \mu \mathrm{s}$, whereas it becomes markedly more rough when the duration is lower or higher than $500 \mu \mathrm{s}$.

(3) The examination of the relationship between the duty factor and the characteristics of the alloyed layer reveals that the layer achieves the maximal thickness and hardness and optimal surface hardness when the duty factor is $50 \%$.

(4) Results of the analysis of the alloyed layer with EPMA show that the silicon and iron contained in the Fe75 mass $\%$ Si electrode effectively dissolve into the surface of $5083 \mathrm{Al}$ alloy and the content of the dissolved elements reduces with the increase in the distance from the discharge surface.

(5) Polarization curves of the alloyed layer obtained with different machining parameters show that the current density of the layer observed with different discharge currents tends to increase with the increase in the discharge current. However, the density shows no evident change in the same condition when the pulse duration and duty factor vary.

(6) Results of X-ray diffraction on the alloyed layer reveal that $\mathrm{Si}, \beta \mathrm{Al}, \mathrm{Al}_{3} \mathrm{Fe}$ and $\mathrm{AlFeSi}$ are the primary constituent phases. TEM examinations show that the matrix of the alloyed layer is an amorphous-like structure, whereas the matrix contains fine needle-like $\mathrm{Si}$ particles, block-like $\mathrm{Si}$ particles and nano-size $\mathrm{Al}_{4.5} \mathrm{FeSi}$ and $\mathrm{Al}_{13} \mathrm{Fe}_{4}$ particles.

\section{Acknowledgment}

This work was financially supported by the National Science Council of Taiwan for which we are grateful (Contract No. NSC 95-2221-E-269-005).

\section{REFERENCES}

1) J. R. Davis and P. Allen: Metals handbook, Properties and Selection: Nonferrous alloys and Special Purpose Materials, 2, 10. ed., (ASM International, 1990) pp. 92-93.

2) H. G. Lee, J. Simao, D. K. Aspinwall, R. C. Dewes and W. Voice: J. Mater. Process. Technol. 149 (2004) 334-340.

3) J. Simao, H. G. Lee, D. K. Aspinwall, R. C. Dewes and E. M. Aspinwall: Int. J. Machine tools Manuf. 43 (2003) 121-128.

4) S. Kumar, R. Singh, T. P. Singh and B. L. Sethi: J. Mater. Process. Technol. 209 (2009) 3675-3687.

5) G. E. Totten and D. S. Mackenzie: Handbook of Aluminum, 2, (Marcel Dekker, Inc. New York, 2003) pp. 549-551.

6) N. Mohri, N. Saito and Y. Tsunekawa: CIRP Annals 42 (1993) 219222.

7) Y. Tsunekawa, M. Okumiya and N. Mohri: Mater. Sci. Eng. A 174 (1994) 193-198.

8) Y. Tsunekawa, M. Okumiya, N. Mohri and E. Kuribe: Mater. Trans. JIM 38 (1997) 630-635.

9) M. Okumiya, Y. Tsunekawa, K. Fukaya and N. Mohri: Mater. Trans. 42 (2001) 1717-1722.

10) H. M. Lin and T. S. Lui: J. Japan Soc. Heat Treat. (Netsu Shori) 49 (2009) 331-334.

11) G. Boothroyd and W. A. Knight: Non-conventional Machining processes, in Fundamentals of Machining and Machine Tools, (Marcel Dekker, Inc., New York, 1989) pp. 491-493. 